Seminar Nasional Teknologi Informasi dan Kedirgantaraan (SENATIK)

Vol. II, 26 November 2016, ISSN: 2528-1666

\title{
IDENTIFIKASI TANAMAN KACANG-KACANGAN BERDASAR ZAT HARA LAHAN MENGGUNAKAN METODE ELECTRE (STUDI KASUS:DI KABUPATEN GUNUNGKIDUL)
}

\author{
Yuliani Indrianingsih, Dwi Nugraheny \\ Program Studi Teknik Informatika, STT "Adisutjipto" \\ Jln. Janti Blok R Lanud Adisutjipto Yogyakarta \\ Email: yulistta@gmail.com
}

\begin{abstract}
This study aims to improve the economic value of farmers' land, so the land can be planted with legumes right by the soil nutrient. Many farming communities are still using the self-taught learning and experience from generation to generation in the determination of the types of legumes were planted them, causing yields are not optimal. And so we need a system that can help farmers to determine the type of legumes matching based nutrient soil to be processed. The study was conducted in the five District in Gunungkidul for data collection in the field. The results of data collection in the field can be a benchmark for decision makers farmers to determine the type of legume crops to be planted based on the criteria of soil nutrients. Criteria are a barometer of determining the type of legumes is the KTK, base saturation, $\mathrm{O}, \mathrm{Ca}, \mathrm{C} / \mathrm{N}$, Magnesium, Carbon. Determining the level of importance of each criterion and to calculate the value of suitability types of legumes based on each of these criteria were analyzed using ELECTRE. The results showed that soybean plants grown in the District Paliyan match with the value 2.208. With this system shows that the ELECTRE method can be applied to the identification of legume-based content of nutrients. Thus increasing the productivity of agricultural land.
\end{abstract}

Keywords : Identification, legumes, Electre

\section{Pendahuluan}

Sebagai Negara agraris, sebagian penduduknya memanfaatkan bercocok tanam untuk hidup dan juga bekerja, maka Indonesia sangat peka terhadap lahan-lahan pertanian. Ketahanan pangan Indonesia tergolong rawan mengingat areal yang diperuntukkan tanaman pangan sangat terbatas. Ancaman akan semakin besar bila konversi lahan produktif menjadi lahan non pertanian tidak bisa dikendalikan. Makanan pokok masyarakat Indonesia hanya menggantungkan produksi pangannya pada area lahan sawah yang semakin menyempit. Oleh karenanya pemerintah harus mengambil langkah-langkah strategis guna mewujudkan ketahanan pangan.

Upaya meningkatkan ketahanan pangan menghadapi berbagai kendala sangat kompleks. Untuk mengatasinya dengan pencanangan beberapa program secara simultan, salah satu diantaranya mengarahkan perluasan area tanaman pangan ke lahan kering. Potensi luasannya yang besar dan aksesibilitasnya baik, memiliki karakteristik sangat besar baik karakter fisik, kimia maupun biologi. Kualitas lahan kering adalah karakteristik spesifik lahan suatu wilayah dipetakan dalam satu satuan lahan. Persyaratan tumbuh tanaman pangan berbeda dibandingkan tanaman perkebunan. Lahan yang memiliki kualitas yang baik sesuai persyaratan tumbuh tanaman dikatakan suitable. Oleh karenanya, kualitas lahan kering perlu ditetapkan melalui proses identifikasi di lapangan maupun di laboratorium.

Berbagai macam masalah yang dapat diselesaikan dengan sistem ini, salah satunya adalah penentuan jenis tanaman kacang-kacangan berdasarkan kandungan zat hara tanah. Tanaman kacang-kacangan merupakan tanaman kedua, setelah padi, yaitu kacang tanah, kedelai, kacang 
hijau. Tanaman ini mempunyai nilai ekonomis yang lebih tinggi dibanding tanaman ubi kayu yang banyak ditanam petani. Penentuan jenis tanaman kacang-kacangan ini akan sangat bermanfaat bagi masyarakat umum khususnya yang berprofesi sebagai petani, karena dengan adanya sistem ini maka petani dapat menentukan jenis tanaman kacang-kacangan yang cocok untuk ditanam di lahan mereka. Sehingga dapat memperbaiki kesejahteraan petani.

Wilayah Kabupaten Gunungkidul sebagian besar kurang subur, lahan kering dan tandus serta pengairan kurang, karena masih banyak pegunungan kapur di wilayah tersebut. Tanaman padi jarang dijumpai di wilayah tersebut dan hanya padi gogo dan ubi kayu yang banyak ditanam di lahan. Sehingga dalam menentukan jenis tanaman yang cocok untuk lahan itu, hanya berdasar otodidak dan pengalaman, serta turun-temurun dari nenek moyang. Sering terjadi gagal panen, karena tak ada kesesuaian antara jenis tanaman yang ditanam dengan kondisi lahan. Hal ini mengakibatkan nilai ekonomis petani menurun, sehingga dibutuhkannya suatu sistem yang dapat membantu agar hasil panen pertanian lebih maksimal berdasar kandungan zat hara atau zat kimiawi tanah.

Sistem yang dibuat ini akan berusaha membantu mengatasi kesulitan yang dihadapi petani agar dapat maksimal dalam pengolahan lahan pertanian yang sesuai dengan kandungan zat lahan. Sistem ini menggunakan metode ELECTRE sehingga dapat diperoleh cara identifikasi yang tepat, tanaman jenis kacang-kacangan yang ditanam berdasar kandungan zat hara lahan. Kajian pustaka terdahulu telah dilakukan penelitian di bidang pertanian tentang optimalisasi lahan kering untuk jagung di Provinsi Gorontalo. Usaha tersebut untuk konservasi tanah dan air menahan lajunya erosi. Banyak petani menanam tanaman jagung di lahan yang kering dan berlereng tanpa tindakan konservasi tanah dan air. Sehingga erosi tanah dan degradasi lingkungan tumbuh begitu besar dan berdampak pada keberlanjutan usaha tani jagung [1].

Pada tahun yang sama dilakukan juga pengolahan lahan kering di DAS Limboto Provinsi Gorontalo untuk pertanian berkelanjutan. Pada penelitian itu diterapkan beberapa strategi pengolahan sistem budi daya dan sistem pengelompokan tanaman dalam satu bentang lahan, penentuan pola tanaman yang tepat. Dalam hal pemanfaatan lahan kering harus ada sinkronisasi koordinasi antar institusi pemerintah dengan melibatkan petani untuk menghindari tumpang tindih kepentingan [2].

Penelitian selanjutnya dilakukan penelitian optimalisasi pengelolaan lahan kering untuk pengembangan tanaman pangan. Dalam menggali potensi lahan kering di masing-masing wilayah diperlukan pemilihan paket teknologi yang sesuai dengan kondisi spesifik lokasi. Mengingat tingkat keragaman yang ada pada lahan kering baik lingkungan fisik, sosial ekonomi, ramah dan aman lingkungan menuju pertanian berkelanjutan [3].

\section{Metode Penelitian}

Penelitian ini dilakukan dengan observasi langsung di wilayah 5 (lima) Kecamatan di Kabupaten Gunungkidul, serta melakukan wawancara dengan Petugas BP3K Pertanian Kecamatan, yaitu proses komunikasi dan pengisian data tanaman. Lokasi pengambilan data dilakukan di Kecamatan Panggang, Paliyan, Playen, Wonosari dan Gedangsari Kabupaten Gunungkidul. Pemilihan lokasi berdasar letak geografisnya, dengan struktur tanah yang berbeda.

Dalam proses perhitungan ada beberapa kriteria tanaman yang akan digunakan, yaitu :

1. Kapasitas Tukar Kation (KTK)

2. Kejenuhan basa (KB)

3. $\mathrm{PHO}$

4. $\mathrm{C} / \mathrm{N}$

5. Fosfor $(\mathrm{P})$

6. Kalium (K)

7. Natrium $(\mathrm{Na})$

8. $\operatorname{Kalsium}(\mathrm{Ca})$

9. Magnesium $(\mathrm{Mg})$

10. Carbon $(\mathrm{C})$

Dengan rating kecocokan pada setiap kriteria, dinilai dengan angka $1-5$, di mana setiap angka memiliki predikat tersendiri yaitu :

1. Sangat Kurang $=1$.

2. Kurang $=2$.

3. Cukup $=3$.

4. Baik $=4$.

5. Sangat Baik $=5$.

Dari setiap penilaian yang telah dilakukan oleh Petugas BP3K Pertanian akan mengisi kriteria seperti di atas. 
Dari sistem yang telah dibuat dapat dihasilkan diagram konteks seperti pada gambar 1 sebagai berikut:

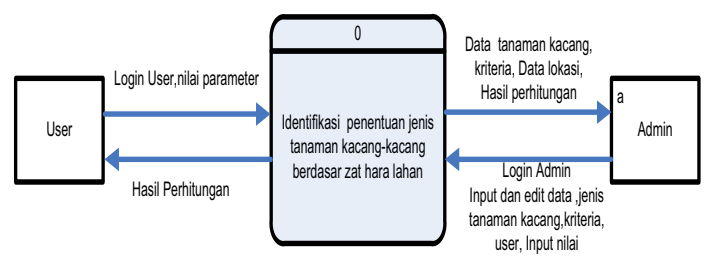

Gambar 1 Diagram konteks

Pada gambar 1 menerangkan bahwa user melakukan login sesuai hak akses yang telah ditentukan. User dalam hal ini Petugas BP3K Pertanian Kecamatan dapat mendaftar untuk menjadi user baru, melalukan input dan edit data. Selain itu user juga dapat melihat dan mencetak data. Untuk admin dapat masuk kedalam sistem dengan melakukan login sebagai admin dimana hak akses yang di dapatkan admin yaitu dapat mengupdate semua data.

Selanjutnya dibuat tahapan penelitian menggunakan flowchart sebagai berikut :

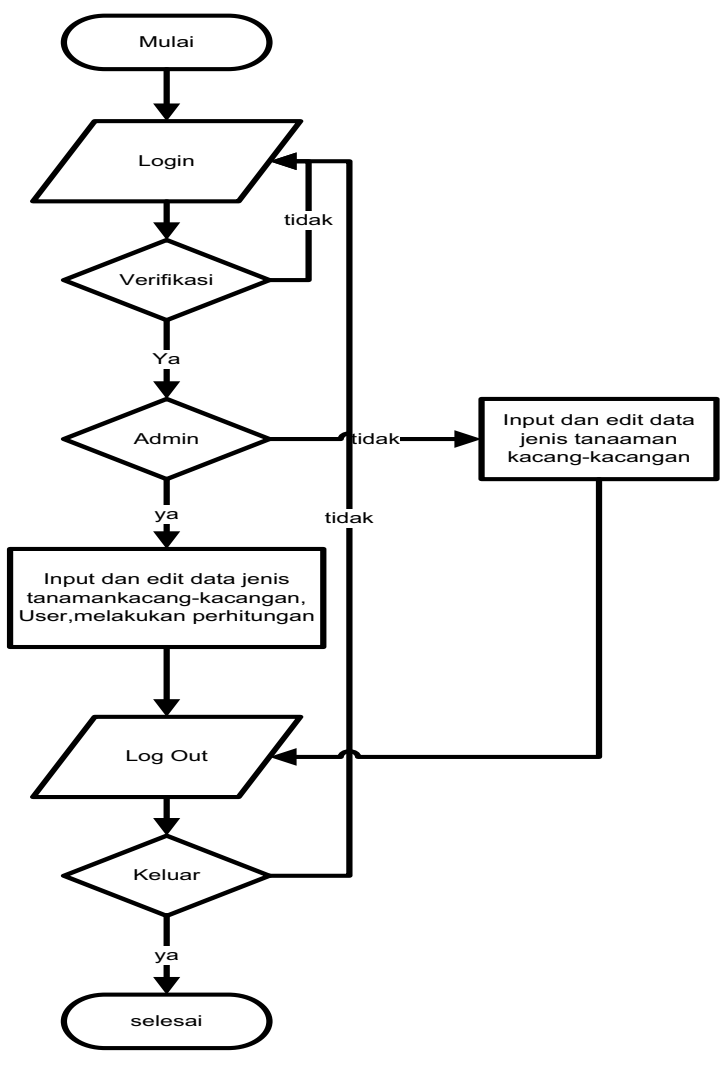

Gambar 2 Flowchart
Metode yang digunakan untuk identifikasi penentuan jenis tanaman kacang-kacangan yaitu metode Electre. Metode ELECTRE termasuk pada metode analisis pengambilan keputusan multikriteria yang berasal dari Eropa pada tahun 1960an [4]. ELECTRE adalah akronim dari Elimination Et Choix Traduisant la Realite atau dalam bahasa inggris berarti Elimination and Choice Expressing Reality.Metode ini merupakan salah satu metode pengambilan keputusan multikriteria berdasarkan pada konsep outranking dengan menggunakan perbandingan

berpasangan dari alternatif - alternatif berdasarkan setiap kriteria yang sesuai. Metode ELECTRE digunakan pada kondisi di mana alternatif yang kurang sesuai dengan kriteria dieliminasi dan alternatif yang sesuai dapat dihasilkan. Dengan kata lain, ELECTRE digunakan untuk kasus - kasus dengan banyak alternatif namun hanya sedikit kriteria yang dilibatkan. Suatu alternatif dikatakan mendominasi alternatif lainnya jika satu atau lebih kriterianya melebihi ( dibandingkan dengan kriteria alternatif yang lain ) dan sama dengan kriteria lain yang tersisa [5].

Langkah - langkah yang dilakukan dalam penyelesaian masalah menggunakan metode ELECTRE adalah sebagai berikut :

1. Normalisasi matrik keputusan.

Dalam prosedur ini setiap atribut diubah menjadi nilai yang compareable. Setiap normalisasi dapat dilakukan dengan persamaan (1) yaitu:

$$
r_{i j}=\frac{x_{j}}{\sqrt{\sum_{i=1}^{m} x_{j}^{2}}}, \ldots . .(1)
$$

untuk $\mathrm{i}=1,2,3, \ldots, \mathrm{m}$ dan $\mathrm{j}=1,2,3, . . \mathrm{n}$

dan $\mathrm{x}_{\mathrm{ij}}=$ variabel keputusan

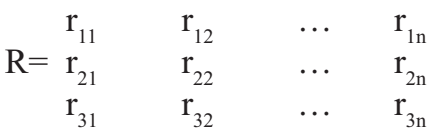

Sehingga diperoleh matrik $\mathrm{R}$ hasil normalisasi.

2. Pembobotan pada matriks yang telah di normalisasi.

Pada langkah kedua ini akan dicari vektor matrik dengan cara mengkalikan matrik $\mathrm{R}$ dengan bobot. 


$$
\begin{array}{clcc}
\mathrm{V}=\mathrm{R} . \mathrm{W} & \text {, dimana } & W \text { adalah } \\
\mathrm{w}_{1} & 0 & \ldots & 0 \\
0 & \mathrm{w}_{2} & \ldots & 0 \\
0 & 0 & \ldots & \mathrm{w}_{3}
\end{array}
$$

Yaitu $V$ adalah vektor dan $W$ adalah bobot.

Dikarenakan hasil dari metode ELECTRE bukan perankingan maka langkah penyelesaian pada metode ini hanya sampai pada langkah ke-2 yaitu pembobotan matriks untuk menentukan perankingan dari metode ELECTRE.

\section{Hasil dan Pembahasan}

Data hasil perolehan dari Petugas BP3K kemudian diolah menggunakan metode Electre

Berikut ini adalah hasil penilaian tanaman kacang-kacangan oleh Petugas BP3K Pertanian.

Tabel 1. Hasil Penilaian Tanaman Kacang-kacangan di Kecamatan Paliyan oleh PetugasBP3K Pertanian

\begin{tabular}{|l|l|l|l|l|l|l|l|l|l|l|}
\hline & K1 & K2 & K3 & K4 & K5 & K6 & K7 & K8 & K9 & K10 \\
\hline Tnm 1 & C & C & B & B & B & B & B & B & K & B \\
\hline Tnm2 & B & K & SB & K & B & B & C & B & K & C \\
\hline Tnm 3 & B & K & B & B & B & B & B & B & K & B \\
\hline
\end{tabular}

Keterangan:

$\begin{array}{ll}\text { SB } & \text { : Sangat Baik } \\ \text { B } & \text { : Baik } \\ \text { C } & \text { : Cukup } \\ \text { K } & \text { : Kurang }\end{array}$

Implementasi sistemnya pada gambar di bawah ini:

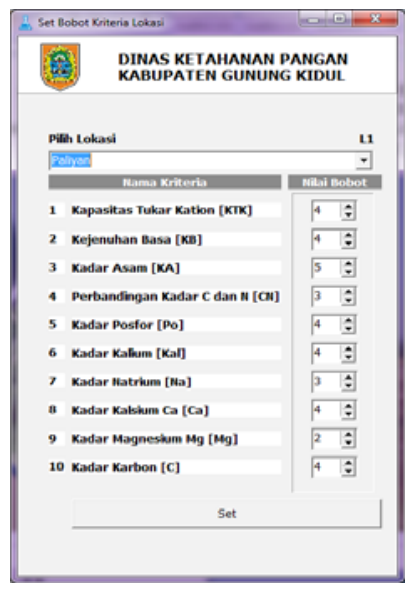

Gambar 3 Tampilan nilai bobot kriteria Metode Electre
Kemudian dilakukan normalisasi matriks seperti pada persamaan 1 di atas, perhitungannya yaitu:

Perhitungan pada kolom 1

$$
\begin{aligned}
& r_{\mathrm{II}}=\frac{3}{\sqrt{3^{2}+4^{2}+4^{2}}}=\frac{3}{\sqrt{4}}=0.4 \\
& r_{3}=\frac{4}{\sqrt{3^{2}+4^{2}+4^{2}}}=\frac{4}{\sqrt{4}}=0.6 \\
& r_{3}=\frac{4}{\sqrt{3^{2}+4^{2}+4^{2}}}=\frac{4}{\sqrt{4}}=0.6
\end{aligned}
$$

Untuk perhitungan kolom 2 sampai kolom 10 caranya sama seperti di atas. Dari perhitungan di atas selanjutnya dibuat matriks ternormalisasi $(\mathrm{R})$ yaitu:

Matriks ternormalisasi $R$ sebagai berikut :

$R=\left[\begin{array}{llllllllll}0.470 .73 & 0.53 & 0.67 & 0.58 & 0.58 & 0.63 & 0.58 & 0.58 & 0.63 \\ 0.63 & 0.49 & 0.66 & 0.33 & 0.58 & 0.58 & 0.47 & 0.58 & 0.58 & 0.47 \\ 0.63 & 0.49 & 0.53 & 0.67 & 0.58 & 0.58 & 0.63 & 0.58 & 0.58 & 0.63\end{array}\right]$

Proses perankingan diambil dari data tabel 1 dikalikan dengan matriks yang ternormalisasi, yaitu: $=\mathrm{R} * \mathrm{~W}$

$$
\begin{array}{r}
V_{2}=\left(3^{*} 0.47\right) ;(3 * 0.73) ;(4 * 0.53) ;(4 * 0.67) ;(4 * 0.58) ;(4 * 0 . \\
58) ;(-4 * 0.63) ;(-4 * 0.58) ;(-2 * 0.58) ;(-4 ; 0.63) \\
V_{2}=(4 * 0.63) ;(2 * 0.49) ;\left(4^{*} 0.66\right) ;(2 * 0.33) ;(4 * 0.58) ;(4 * 0 . \\
58) ;(-3 * 0.47) ;(-4 * 0.58) ;(-2 * 0.58) ;(-3 ; 0.47) \\
V_{3}=(4 * 0.63) ;(2 * 0.49) ;(4 * 0.53) ;(4 * 0.67) ;(4 * 0.58) ;(4 * 0 . \\
58) ;(-4 * 0.63) ;(-4 * 0.58) ;(-2 * 0.58) ;(-4 ; 0.63)
\end{array}
$$

Proses selanjutnya melakukan perankingan untuk proses perankingan dapat menggunakan persamaan sebagai berikut:

Dengan $\mathrm{m}=$ kode tanaman; dan $\mathrm{n}=1,2,3 \ldots \mathrm{n}$.

$$
\begin{aligned}
& \operatorname{Pro}_{01}=\frac{\sum v_{1}}{3}=\frac{1.87+2.91+2.65+2.00+2.31+2.31-1.87-2.31-1.16-2.491}{3}=2.072 \\
& \operatorname{Pro}_{02}=\frac{\sum v_{2}}{3}=\frac{2.12+1.53+2.28+1.41+2.84+2.10-1.59-1.74-1.71-2.90}{3}=2.208 \\
& \operatorname{Pr}_{003}=\frac{\sum v_{3}}{3}=\frac{2.12+1.53+1.68+1.89+2.28+2.85-1.59-1.74-1.71-2.90}{3}=1.957
\end{aligned}
$$

Nilai terbesar ada pada Tnm02 dengan hasil 2.208 sehingga didapatkan alternatif terbaik yaitu dari tanaman kedelai untuk di tanam di lahan pertanian di Kecamatan Paliyan. Sesuai perhitungan pada implementasi sistem yang dibuat pada gambar 4 sebagai berikut: 


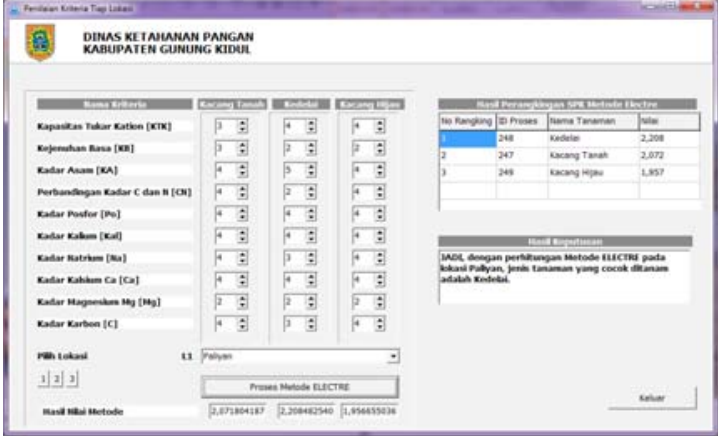

Gambar 4 Tampilan hasil perhitungan menggunakan Metode Electre

Berdasarkan perhitungan dan implementasi sistem yang dibuat, diperoleh jenis tanaman terpilih seperti tabel berikut ini:

Tabel 2 Jenis Tanaman Terpilih pada Masingmasing Lokasi

\begin{tabular}{|l|l|c|c|}
\hline No & \multicolumn{1}{|c|}{$\begin{array}{c}\text { Nama } \\
\text { Lokasi }\end{array}$} & $\begin{array}{c}\text { Jenis Tanaman } \\
\text { Terpilih }\end{array}$ & Nilai \\
\hline 1 & Paliyan & Kedelai & 2,207 \\
\hline 2 & Playen & Kacang hijau & 0,4523 \\
\hline 3 & Panggang & Kacang tanah & 0,2654 \\
\hline 4 & Gedangsari & Kedelai & 1,7861 \\
\hline 5 & Wonosari & Kacang tanah & 0,9227 \\
\hline
\end{tabular}

Hasil implementasi menggunakan metode Electre, diperoleh hasil tanaman yang cocok untuk Kecamatan Paliyan adalah tanaman kedelai. Dengan sistem ini Metode Electre dapat digunakan untuk identifikasi penentuan jenis tanaman kacangkacangan berdasar kandungan zat hara tanah. Sehingga produktivitas lahan pertanian meningkat, karena wilayah Kabupaten Gunungkidul mempunyai potensi yang besar untuk ditanami tanaman kacangkacangan berdasar struktur tanahnya.

\section{Kesimpulan}

1. Identifikasi untuk menentukan jenis tanaman kacang-kacangan berdasar kandungan zat hara lahan di wilayah 5 (lima) Kecamatan di Kabupaten Gunungkidul menggunakan metode Electre berjalan dengan baik.

2. Jenis tanaman kacang-kacangan yang cocok ditanam di Kecamatan Paliyan adalah jenis kedelai, sesuai dengan kandungan unsur hara lahan.
3. Metode Electre merupakan salah satu metode yang dapat diterapkan utuk identifikasi penentuan jenis tanaman kacang-kacangan berdasar kandungan zat hara.

4. Memperbaiki nilai produktivitas lahan yang sesuai dengan unsur hara tanah, sehingga dapat meningkatkan nilai ekonomis petani.

\section{Saran}

Saran yang dapat diberikan untuk perbaikan dan pengembangan dari sistem ini adalah

1. Sistem ini dapat dikembangkan lagi menjadi sistem yang bersifat client server sehingga dapat dieksekusi oleh banyak user.

2. Sistem ini dapat dikembangkan lagi dengan perhitungan yang lainnya misalnya Metode Topsis, SAW, dan AHP, dan berbasis WEB.

\section{Ucapan Terima Kasih}

Ucapan terima kasih dihaturkan kepada Kementrian Riset Teknologi dan Pendidikan Tinggi (Kemenristek Dikti) Republik Indonesia yang sudah membiayai penelitian ini.

\section{DAFTAR PUSTAKA}

[1] Nurdin, 2008, Optimalisasi Produktivitas Lahan Kering Melalui Pengembangan Sistem Usahatani Konservasi Tanaman jagung Di Provinsi Gorontalo, Jurnal Agropolitan Vol.1 No.1, hal 1-12.

[2] Nurdin, 2008, Penggunaan Lahan Kering di DAS Limboto Provinsi Gorontalo Untuk Pertanian Berkelanjutan, Jurnal Litbang Pertanian, vol.3, hal 98-107.

[3] Minardi,S, 2009, Optimalisasi Pengelolaan Lahan Kering Untuk Pengembangan Tanaman Pangan, disampakan pada Pidato pengukuhan Guru Besar Ilmu Tanah pada tanggal 26 Februari 2009, di Fakultas Pertanian UNS, Solo.

[4] Wolfgang, J., Bernroider, E, 2005, MultiCriteria Decision Making An Application Study of ELECTRE \& TOPSIS, Graha Ilmu, Yogyakarta. 
[5] Kusumadewi, Sri., Hartati, S., Harjoko, A., dan Wardoyo, R., 2006, Fuzzy MultiAttribute Decision Making (FUZZY MADM), Graha Ilmu, Yogyakarta.

[6] Jogiyanto, HM., 2005, Analisis dan Desain Sistem Informasi: Pendekatan Terstruktur Teori Dan Praktik Aplikasi Bisnis, Andi offset, Yogyakarta.
[7] Kusrini, 2007, Konsep dan Aplikasi Sistem Pendukung Keputusan, Andi offset, Yogyakarta.

[8] Turban E., Aronson J.E., dkk, 2003, Decision Support Systems and Intelligent Systems (Sistem Pendukung Keputusan dan Sistem Cerdas, Andi Offset, Yogyakarta. 